\title{
Denosumab Tedavisi Alan Postmenopozal Osteoporozlu Hastalarda Hasta Memnuniyeti, Sırt Ağrısı ve Kemik Mineral Dansitometri T-Skorlarının Değerlendirilmesi
}

\author{
Evaluation of Patient Satisfaction, Back Pain, and Bone Mineral Densitometry T-Scores in \\ Patients with Postmenopausal Osteoporosis Who Received Denosumab Treatment
}

(D) Gonca Sağlam, DD Dilek Çetinkaya Alişar*

Karadeniz Teknik Üniversitesi Tıp Fakültesi, Fiziksel Tıp ve Rehabilitasyon Anabilim Dalı, Trabzon, Türkiye

*Kocaeli Devlet Hastanesi, Fiziksel Tıp ve Rehabilitasyon Kliniği, Kocaeli, Türkiye

\section{Öz}

Amaç: Bu çalışmada postmenopozal osteoporozlu hastalarda denosumab tedavisinin kemik mineral dansitometri (KMD) T-skorları, sırt ağrısı ve hasta memnuniyeti üzerine etkilerini belirlemek amaçlandı.

Gereç ve Yöntem: Çalışmaya postmenopozal osteoporoz tanısılla 2 yıl boyunca düzenli denosumab tedavisi alan 134 hasta dahil edildi. Sosyo-demografik verilerin toplanmasının ardından hastaların denosumab tedavisinden sonra KMD T-skorlarındaki ve vizüel analog skala (VAS) ile sırt ağrısındaki iyileşme değerlendirildi. Likert ölçeği ile hasta memnuniyeti, fiziksel fonksiyonlardaki ve yaşam kalitesindeki artış analiz edildi. Bulgular: Tedavi öncesi değerlere göre, tedavi sonunda sırt ağrısı ile vertebra ve femur T-skorlarında istatistiksel olarak anlamlı iyileşme izlendi

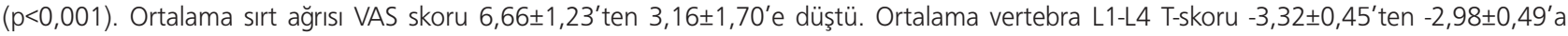
$(p<0,001)$, femur boyun T-skorları ise $-1,98 \pm 1,26^{\prime}$ dan $-1,86 \pm 1,25^{\prime}$ e yükseldi $(p<0,001)$. Hastaların \%26,87'si denosumab tedavisinin çok etkili olduğunu, \%47,76'sı ise etkili olduğunu bildirdi. Fiziksel fonksiyonlardaki iyileşme bakımından hastaların \%36,57'si denosumab tedavisini çok etkili, \%32,09'u etkili olarak değerlendirdi. Hastaların \%28,36'sı yaşam kalitesi açısından denosumabı çok etkili olarak değerlendirirken $\% 43,28$ 'i etkili olarak değerlendirdi.

Sonuç: Bu çalışmanın sonuçları, denosumab enjeksiyonunun postmenopozal osteoporoz tedavisinde T-skorlarını artıran, sırt ağıısını azaltan ve hastalarda memnuniyet sağlayan etkili ve pratik bir tedavi seçeneği olduğunu göstermektedir.

Anahtar kelimeler: Denosumab, kemik mineral yoğunluğu, osteoporoz, sırt ağrısı

\section{Abstract}

Objective: This study aimed to determine the effects of denosumab therapy on bone mineral densitometry (BMD) T-scores, back pain, and satisfaction in patients with postmenopausal osteoporosis.

Materials and Methods: This study included 134 patients diagnosed with postmenopausal osteoporosis and regularly received denosumab treatment for 2 years. Socio-demographic data were collected, and patients were evaluated after denosumab therapy in BMD T-scores and back pain improvement using a visual analog scale (VAS). Patient satisfaction, physical function improvement, and quality of life were analyzed using a Likert scale.

Results: The pretreatment values revealed a statistically significant improvement in vertebral and femoral T-scores and back pain after treatment $(p<0.001)$. The mean back pain VAS score reduced from $6.66 \pm 1.23$ to $3.16 \pm 1.70$. The mean vertebral L1-L4 T-scores increased from $-3.32 \pm 0.45$ to $-2.98 \pm 0.49(p<0.001)$, and femoral neck T-scores increased from $-1.98 \pm 1.26$ to $-1.86 \pm 1.25$ ( $p<0.001$ ). Denosumab treatment was very satisfying for $26.87 \%$ of patients, whereas $47.76 \%$ of patients found it satisfying. In the improvement in physical functions, $36.57 \%$ of patients evaluated denosumab treatment as very effective and $32.09 \%$ as effective. Additionally, $28.36 \%$ of patients evaluated denosumab as very effective in regard to the quality of life, whereas $43.28 \%$ evaluated it as effective.

Conclusion: Study results demonstrate that denosumab injection is a practical and satisfactory treatment option that effectively improves T-scores and back pain in postmenopausal osteoporosis treatment.

Keywords: Denosumab, bone mineral density, osteoporosis, back pain

Yazışma Adresi/Address for Correspondence: Uzm. Dr. Gonca Sağlam, Karadeniz Teknik Üniversitesi Tıp Fakültesi, Fiziksel Tıp ve Rehabilitasyon Anabilim Dalı, Trabzon, Türkiye Tel.: +90 5054525688 E-posta: goncasaglam@hotmail.com ORCID ID: orcid.org/0000-0001-7713-4435 Geliş Tarihi/Received: 09.11.2020 Kabul Tarihi/Accepted: 24.12.2020

๑ Telif Hakkı 2021 Türkiye Osteoporoz Derneği /Türk Osteoporoz Dergisi, Galenos Yayınevi tarafından yayınlanmıştır. 


\section{Giriş}

Osteoporoz (OP) azalmış kemik kitlesi ve gücü ile karakterize, etkilenen bireylerde kırık riskinde artış izlenen bir kronik iskelet sistemi hastalığıdır. Tüm dünyada postmenopozal kadınlar başta olmak üzere milyonlarca insanı etkilemektedir. Dünyada beklenen yaşam süresinin artması ve yaşlanan nüfus ile her ülkede ve her ırkta postmenopozal kadın sayısı artmakta ve OP ile ilişkili kırık görülme sıklığı artmaktadır (1).

OP tedavisine yaklaşımda en önemli ilkeler uygun ve etkili tedavinin sağlanması, kemik kütlesinin korunarak ağrının azaltılması ve kırık oluşumunun önlenmesidir (2). Osteoporotik kırıkların önlenmesinde antirezorptif ve anabolik ajanlar olmak üzere iki temel ilaç grubu bulunmaktadır $(3,4)$. Bifosfonatlar uzun yıllardır OP tedavi protokollerinde ilk sırada yer almaktadırlar. Ancak bifosfonat kullanımı ile mandibula ve maksillada osteonekroz, gastrointestinal sorunlar, ateş ve grip belirtileri, elektrolit bozukluğu, kas ve kemik ağrıları gibi yan etkilere rastlanabilmektedir (5). Kontrendikasyonlar ve intolerans nedeniyle oral bifosfonat alamayan veya kırık riski yüksek olan hastaların denosumab veya intravenöz zoledronik asit kullanımı uygundur. Çok yüksek kırık riskinde ise anabolik etkili ve maliyeti daha yüksek olan teriparatid önerilmektedir (6).

Denosumab, anahtar kemik rezorpsiyon mediyatörü olan nükleer faktör-B ligandı hedefleyen bir insan monoklonal (IgG2) antikoru olup bifosfonatlar gibi antirezorptif bir ajandır. Kemik mikromimarisinde osteoklast öncü hücrelerinin farklılaşmasını ve osteoklast fonksiyonunu inhibe eder ve osteoklastların yaşam sürelerini azaltarak kırık riskini azaltır. Ilaç her 6 ayda bir deri altından enjeksiyon ile tekrarlanır. Postmenopozal OP dahil yüksek kırık riski olan, diğer tedavilerin başarısızlığı veya diğer ilaçların intoleransı durumunda OP tedavisinde kullanılabilecek bir ajandır (7).

Bu çalışmada postmenopozal OP tedavisinde kullanımı son yıllarda giderek artan ancak ülkemizde yeterli klinik çalışması olmadığı görülen denosumab tedavisinin sırt ağrısına ve kemik mineral dansitometrideki (KMD) T-skorlarına etkisi ile tedavi alan hastalardaki hasta memnuniyetini değerlendirmek amaçlandı.

\section{Gereç ve Yöntem}

Bu çalışmaya 2018-2020 yılları arasında postmenopozal OP tanısıyla $60 \mathrm{mg} / 6$ ay subkütan denosumab ile 2 yıl düzenli olarak tedavi edilerek toplamda 4 doz denosumab enjeksiyonu uygulanan, 2,5 yılın sonunda, 5. doz denosumab enjeksiyonu için fizik tedavi ve rehabilitasyon polikliniğine başvuran, 5070 yaş aralığında 134 hasta dahil edildi. Ülkemizde geçerli sağlık uygulama tebliği kapsamında denosumab tedavisi yalnız bifosfonatları tolere edemeyen veya bifosfonatlara yeterli yanıt alınamayan hastalara verilebildiğinden çalışmamızdaki hastalar da bu koşula uygundu. Sekonder OP, hipogonadizm, akut vertebral kırık veya kemik metastazı tanılı, OP dışı metabolik hastalığı olan (Paget veya renal osteodistrofi), travma öyküsü olan veya OP dışında sırt ağrısı yapabilecek etiyoloji tespit edilen hastalar çalışmaya alınmadı.
Hastaların yazılı onamı alındıktan sonra demografik ve klinik verileri kaydedildi. Poliklinik kayıt sistemi incelenerek, retrospektif olarak 2 yıl önceki KMD değerleri ile son doz öncesi KMD değerleri kaydedildi. Tedavi öncesi ve sonrası 25-hidroksivitamin $D_{3}\left[25-(O H) D_{3}\right]$ değerleri incelendi. Vizüel analog skala (VAS) ile 0-10 aralığında değerlendirilen sırt ağrısı şiddeti skoru olgu rapor formuna işlendi. Tedavi sonrası hasta memnuniyeti, fiziksel fonksiyonlardaki ve yaşam kalitesindeki artış 1 (etkisiz) - 5 (çok etkili) aralığında Likert ölçeği ile analiz edildi. Vertebral kompresyon fraktürlerini değerlendirmek için tedavi başlangııındaki ve tedavi sonundaki dorsolomber iki yönlü direkt grafiler incelendi. Direkt grafilerde T1-L5 aralığındaki vertebra yükseklikleri bir fizik tedavi ve rehabilitasyon uzman hekimi tarafından değerlendirildi. Bir vertebranın ön, arka veya orta yükseklik ölçümlerinden herhangi birinin en yakın normal vertebranın yükseklik ölçümüne göre en az \%20 azalmış olması vertebral kırık olarak tanımlandı (8). Hastaların kemik mineral yoğunluğu Stratos dR 2D Fan Beam Dexa model cihaz ile ölçüldü ve genç erişkin kemik yoğunluk değerlerine göre belirlenen T-skorları ile değerlendirildi. Dünya Sağlık Örgütü sınıflamasına uygun olarak T-skorunun -2,5 altı olması OP olarak tanımlandı. Çalışmamızdaki hastaların hepsine denosumab yanında $880 \mathrm{IU} /$ gün D vitamini ile $1.000 \mathrm{mg} /$ gün kalsiyum (Ca) verilmişti. Hastalar denosumab tedavisi ile herhangi bir yan etki gelişimi olup olmadığı bakımından sorgulandı. Bu çalışmanın yapılabilmesi için Sağlık Bilimleri Üniversitesi Erzurum Bölge Eğitim ve Araştırma Hastanesi Etik Kurul Komitesi'nden gereken etik kurul onayı alındı (karar no: 2020/14-59, tarih: 20.07.2020) ve çalışma Helsinki Bildirgesi'ne uygun olarak gerçekleştirildi.

\section{İstatistiksel Analiz}

İstatistiksel analizler SPSS versiyon 17.0 programı yardımıyla gerçekleştirildi. Değişkenlerin normal dağılıma uygunluğu histogram grafikleri ve Kolmogorov-Smirnov testi ile incelendi. Tanımlayıcı analizler sunulurken ortalama, standart sapma, ortanca değerler kullanıldı. Tedavi öncesi ve sonrası yapılan ölçümlerdeki değişim Wilcoxon testi ile değerlendirildi. Kırık varlığına göre olan değişim ise tekrarlayan ölçümler analizi ile incelendi. Hasta memnuniyeti, fiziksel fonksiyon ve yaşam kalitesi ile ölçülen klinik parametrelerdeki değerlerdeki fark arasındaki ilişki Spearman korelasyon testi ile araştırıldı. P değerinin 0,05'in altında olduğu durumlar istatistiksel olarak anlamlı sonuçlar olarak kabul edildi.

\section{Bulgular}

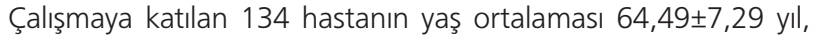
ortalama menopoz süresi ise 17,02 7 ,15 yıldı. Tedavi öncesi vertebra kırığı olan 23 hasta, periferik kırığı olan 19 hasta tespit edildi (Tablo 1). Tedavi öncesi ve sonrası değerlendirilen direkt grafiler sonucu hastaların hiçbirinde yeni vertebral kırık gelişmediği belirlendi. Periferik kırık gelişimi sorgulandığında da hiçbir hastada tedavi süresince gelişen yeni bir kırık olmadığı görüldü. Hastalar ilaç verilirken veya sonrasında ilaca bağlı herhangi bir yan etki gelişimi veya ciddi enfeksiyon belirtmedi. 
Hastaların tedavi sonundaki memnuniyeti sorgulandığında; hastaların \%26,87'si denosumab tedavisini çok etkili, \%47,76'sı etkili bulmaktaydı. Fiziksel fonksiyonlardaki iyileşme bakımından hastaların \%36,57'si denosumab tedavisini çok etkili, \%32,09'u etkili olarak değerlendirdi. Hastaların \%28,36'sı yaşam kalitesi açısından denosumabı çok etkili olarak değerlendirirken \%43,28'i etkili olarak değerlendirdi (Tablo 2).

Hastaların ortalama sırt ağrısı VAS değerleri tedavi öncesinde $6,66 \pm 1,23$ iken tedavi sonunda 3,16 $\pm 1,70$ 'e düştü. Total L1-4 T-skorları ortalaması tedavi öncesi $-3,32 \pm 0,45^{\prime}$ ten tedavi sonrası $-2,98 \pm 0,49^{\prime} a$, femur boyun T-skorları ortalaması ise tedavi öncesi $-1,98 \pm 1,26^{\prime}$ dan tedavi sonunda $-1,86 \pm 1,25^{\prime}$ e geriledi. Sırt ağrısı VAS skorları, L1-4 T-skoru, femur boyun T-skoru ve D vitamini düzeyleri tedavi öncesi ve sonrası karşılaştırıldığında her parametrede istatistiksel olarak anlamlı iyileşme saptandı $(p<0,001)$ (Tablo 3).

Hasta memnuniyeti ve yaşam kalitesi ile sırt ağrısı VAS skorları arasında yüksek düzeyde, fiziksel fonksiyon ile sırt ağrısı VAS skorları arasında orta düzeyde, ters yönlü korelasyon olduğu görüldü. Sırt ağrısı arttıkça hasta memnuniyeti $(r=-0,720)$ $(p<0,001)$, fiziksel fonksiyon $(r=-0,689)(p<0,001)$ ve yaşam kalitesi $(r=-0,738),(p<0,001)$ azalmaktaydı. Hasta memnuniyeti, fiziksel fonksiyon ve yaşam kalitesi ile L1-4 T-skoru arasında ise aynı yönlü korelasyon izlendi (Tablo 4). Vertebra kırığı varlığına göre L1-4 T-skoru ve femur boyun T-skoru değerlerindeki tedavi öncesi ve sonrası değişim karşılaştırıldığında istatistiksel olarak anlamlı farklılık saptanmadı. Ancak, sırt ağrısı VAS değerinin vertebra kırığı olmayanlarda, vertebra kırığı olanlara göre

\section{Tablo 1. Demografik veriler}

\begin{tabular}{|l|l|l|}
\hline & $\mathbf{n}$ & $\%$ \\
\hline Yaş $^{*}$ & $64,49 \pm 7,29$ & 64,00 \\
\hline Menopoz süresi (yıl)* & $17,02 \pm 7,15$ & 15,00 \\
\hline Vertebra kırı̆ı & 23 & $(17,16)$ \\
\hline Periferik kırık & 19 & $(14,18)$ \\
\hline \multicolumn{2}{|l|}{ *n yerine ortalama, standart sapma, \% yerine medyan verilmiştir } \\
\hline
\end{tabular}

tedaviden sonra daha çok azaldığı tespit edildi $(p=0,004)$ (Şekil 1). Periferik kırık varlığına göre sırt ağrısı için değerlendirilen VAS, L1-4 T-skoru ve femur boyun T-skoru değerlerindeki tedavi öncesi ve sonrası değişim karşılaştırıldı. Periferik kırık varlığı ile yalnız L1-4 T-skorundaki değişim arasında anlamlı farklılık saptandı $(p=0,028)$ (Şekil 2).

\section{Tartışma}

OP tedavisinde ilk seçenek antirezorptif ajanlar bifosfonatlar iken günümüzde bu gruba alternatif olarak denosumab öne çıkmaktadır. Postmenopozal OP hastalarında yapılan çalışmalarda denosumab ile kemik mineral yoğunluğunda önemli kazanımlar ve kemik yıkım belirteçlerinde hızlı azalma izlenmiş, vertebra, vertebra dışı ve kalça kırık riskinin de azaldığı belirlenmiştir (9). Plasebo ile karşılaştıııldığında, 24-48 ay boyunca düzenli olarak 6 ayda bir 60 mg denosumab enjeksiyonu yapılan hastaların KMD ölçümlerinde \%6,5-11 oranında artış olabildiği tespit edilmiştir (10). Cummings ve ark. (11) denosumab tedavisi sonrası KMD ölçümlerinde; 3 yll denosumab alanlarda lomber omurgada $\% 9,4$, total kalçada \%4,8, 6 yıl denosumab alanlarda lomber

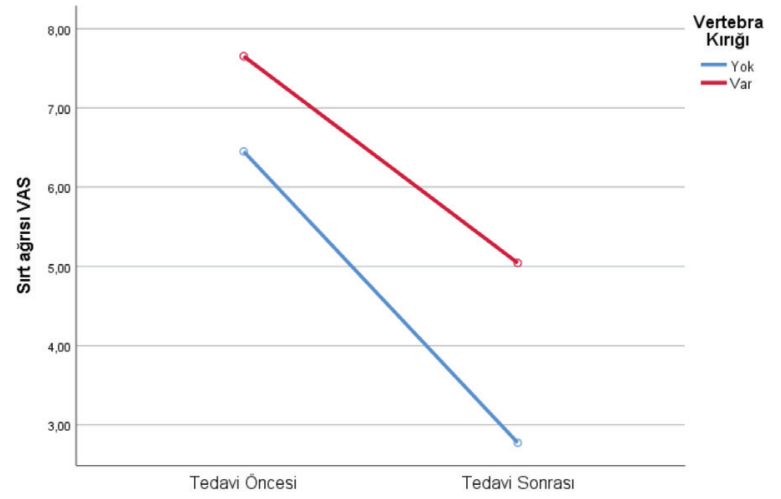

Şekil 1. Vertebra kıı̆ğı varlığına göre sırt ağrısı VAS skorlarındaki değişim

VAS: Vizüel analog skala

Tablo 2. Denosumabın hasta memnuniyeti, fiziksel fonksiyon ve yaşam kalitesi üzerine etkileri

\begin{tabular}{|c|c|c|c|c|c|c|c|c|c|c|}
\hline & \multicolumn{2}{|c|}{ Etkisiz } & \multicolumn{2}{|c|}{ Az etkili } & \multicolumn{2}{|c|}{ Normal etkili } & \multicolumn{2}{|c|}{ Etkili } & \multicolumn{2}{|c|}{ Çok etkili } \\
\hline & $\mathrm{n}$ & $\%$ & $\mathbf{n}$ & $\%$ & $\mathbf{n}$ & $\%$ & $\mathbf{n}$ & $\%$ & $\mathbf{n}$ & $\%$ \\
\hline Hasta memnuniyeti & 4 & $(2,99)$ & 9 & $(6,72)$ & 21 & $(15,67)$ & 64 & $(47,76)$ & 36 & $(26,87)$ \\
\hline Fiziksel fonksiyon & 4 & $(2,99)$ & 12 & $(8,96)$ & 26 & $(19,40)$ & 43 & $(32,09)$ & 49 & $(36,57)$ \\
\hline Yaşam kalitesi & 4 & $(2,99)$ & 15 & $(11,19)$ & 19 & $(14,18)$ & 58 & $(43,28)$ & 38 & $(28,36)$ \\
\hline
\end{tabular}

Tablo 3. Tedavi öncesi ve sonrası VAS ve KMD T-skorları ile D vitamini düzeylerinin karşılaştırılması

\begin{tabular}{|l|l|l|l|l|l|l|l|}
\hline \multirow{2}{*}{} & \multicolumn{3}{|c|}{ Tedavi öncesi } & \multicolumn{3}{c|}{ Tedavi sonrası } & \multirow{2}{*}{ P } \\
\cline { 2 - 8 } & Ortalama & SS & Medyan & Ortalama & SS & Medyan & \\
\hline Sırt ağrısı VAS & 6,66 & $\pm 1,23$ & 7,00 & 3,16 & $\pm 1,70$ & 3,00 & $<0,001$ \\
\hline L1-4 T-skoru & $-3,32$ & $\pm 0,45$ & $-3,20$ & $-2,98$ & $\pm 0,49$ & $-2,60$ & $<0,001$ \\
\hline Femur boyun T-skoru & $-1,98$ & $\pm 1,26$ & $-1,20$ & $-1,86$ & $\pm 1,25$ & $-0,50$ & $<0,001$ \\
\hline D vitamini düzeyi (ng/mL) & 19,00 & $\pm 9,72$ & 17,49 & 31,17 & $\pm 7,94$ & 32,00 & $<0,001$ \\
\hline Wilcoxon testi, VAS: Vizüel analog skala, Ss: Standart sapma, KMD: Kemik mineral dansitometri & & & & \\
\hline
\end{tabular}


omurgada \%15,2, total kalçada \%7,5 artış bildirmişlerdir. Çalışmamızın sonuçlarına bakıldığında lomber bölge T-skorlarında 0,34 (\%10), femur boyun T-skorlarında 0,12 (\%6) kazanım olduğu görüldü. Literatür ile uyumlu olarak hem vertebral hem de femur T-skorlarında görülen anlamlı iyileşme denosumab tedavisinin hem vertebra hem femur üzerinde antirezorptif etkili olduğunu göstermektedir. Çalışmamızda vertebra kırığı olmayan hastalarda vertebra kırığı olanlara göre sırt ağrısında daha çok azalma belirlendi. Bu durum mevcut vertebral kırıkların sırt ağrısını artırıyor olması ile açıklanabilir. Periferik kırıklı hastalarda ise lomber KMD T-skorlarında daha fazla artış olduğu belirlendi. Çalışmamızdaki hastaların tümüne denosumab yanında $880 \mathrm{IU} /$ gün D vitamini ile $1.000 \mathrm{mg} /$ gün Ca verilmişti. Tedavi sonundaki ortalama $25-(\mathrm{OH}) \mathrm{D}_{3}$ ölçümlerinin $31,17 \pm 7,94$ olduğu ve hastalarımızın bu tedaviye de uyumlu olduğu görülmektedir. Yapılan klinik çalışmalarda, denosumab oral bifosfonatlar ve zoledronik asit ile karşılaştııldığında, kemik yoğunluğunu artırma bakımından denosumab biraz daha etkili bulunmuştur $(12,13)$. Diğer yandan, hasta tercihi ve memnuniyeti ile yan etki bildirme açısından yapılan değerlendirmeler de denosumabın bifosfonatlardan daha avantajı olduğuna işaret etmektedir (1416). OP'nin kronik bir süreç olduğu ve uzun süreli ilaç kullanımı söz konusu olduğu düşünülürse hasta uyumu ve memnuniyetinin tedaviye devam bakımından önemi anlaşılacaktır. Yakın zamanlı bir meta-analizde incelenen çalışmaların analizi sonucunda;

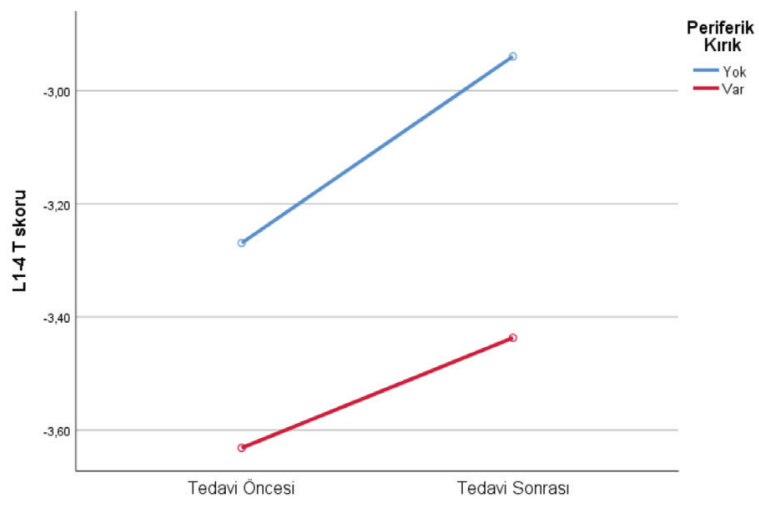

Şekil 2. Periferik kırık varlığına göre L1-4 T-skorlarındaki değişim özellikle postmenopozal OP'li hastaların uygulama şekli, kullanım kolaylığı ve doz aralığının geniş olması nedenleriyle uzun süreli tedavi için oral bisfosfonatlara göre denosumabın daha çok tercih edildiği görülmektedir (12). Çalışmamızdaki hastaların ilaca bağlı memnuniyetlerini değerlendirdiğimizde hastaların \%90,3'ü denosumab tedavisinden yeterince memnun iken ülkemizde bu konuda yapılan bir araştırmada denosumab tedavisi alan postmenopozal OP'li hastaların \%88'inin tedaviden memnun kaldığı görülmüş ve çalışmamızda olduğu gibi bu hasta grubunda herhangi bir yan etki raporlanmamıştır (17). Hastalarımızın KMD T-skorlarındaki yükselmeye, ağıı skorlarında ve yaşam kalitesindeki artışa bakıldığında da bu çalışma ile paralel olduğu görülmektedir.

Yaşı nüfus artışı ile $O P^{\prime}$ nin de giderek artması ve günümüzde fiziksel aktivitenin azalması nedeniyle osteoporotik kırıklarla ilişkili maliyet giderek artmaktadır (18). Bu bakımdan OP'ye yaklaşımda seçilecek ajanın potansiyel yararı ile sağılı bütçesi birlikte göz önüne alınmalıdır (19). Hiligsmann ve Reginster (20) çalışmalarında her ne kadar yüksek maliyetli olsa da iyi bir tedavi seçeneği olduğundan denosumabın maliyet etkin olduğunu göstermişlerdir. Diğer yandan bir meta-analizde postmenopozal OP'nin en uygun maliyetli başlangıç tedavisinin oral alendronat veya parenteral zoledronik asit olduğu belirtilmiştir (21).

Adami ve ark. (22) OP tedavisine yanıtsızlığın en önemli nedeninin tedaviye uyumsuzluk olduğunu saptamışlardır. Tedaviye uyumsuzlukta ilacın yan etki profili önemli bir yere sahiptir. Denosumab ilaç yan etkileri bakımından avantajlı bir seçenektir ancak tedavi öncesi hastalar ilaca bağlı olası riskler açısından değerlendirilmelidir. İmmünosüpresif tedavi alma gibi riskli olan hastalarda enfeksiyon gelişim riski bulunmaktadır. Denosumab tedavisi sonrası bildirilmiş yan etkiler arasında; kas spazmları, atipik femur kırıkları, çene osteonekrozu yanında özellikle kreatinin klirensi $<30 \mathrm{~mL} / \mathrm{dk}$ olduğunda görülebilecek hipokalsemidir (7). Çalışmamızdaki hastalar denosumab tedavisi ile herhangi bir yan etki bildirmemişlerdir. Sheedy ve ark.'nın (13) çalışmasında zoledronik asit alan hastalarda \%29 grip benzeri semptomlar izlenirken denosumab kullanan hiçbir hastada bu bulgular görülmemiştir.

Çalışmamızda retrospektif değerlendirme yapılmış olması, kontrol grubunun olmaması ve ülkemizdeki ilaç geri ödeme

Tablo 4. VAS, KMD T-skorları ve D vitamini değerlerindeki değişim ile hasta memnuniyeti, fiziksel fonksiyon ve yaşam kalitesi arasındaki korelasyonun incelenmesi

\begin{tabular}{|l|l|l|l|l|}
\hline \multicolumn{2}{|c|}{} & Hasta memnuniyeti & Fiziksel fonksiyon & Yaşam kalitesi \\
\hline \multirow{2}{*}{ Sırt ağrısı VAS } & $\mathrm{R}$ & $-0,720$ & $-0,689$ & $-0,738$ \\
\cline { 2 - 5 } & $\mathrm{P}$ & $<0,001$ & $<0,001$ & $<0,001$ \\
\hline \multirow{2}{*}{ L1-4 T-skoru } & $\mathrm{R}$ & 0,221 & 0,189 & 0,292 \\
\cline { 2 - 5 } & $\mathrm{P}$ & 0,011 & 0,029 & 0,001 \\
\hline \multirow{2}{*}{ Femur boyun T-skoru } & $\mathrm{R}$ & 0,103 & 0,144 & 0,114 \\
\cline { 2 - 5 } & $\mathrm{P}$ & 0,239 & 0,098 & 0,191 \\
\hline \multirow{2}{*}{ D vitamini düzeyi } & $\mathrm{R}$ & 0,056 & $-0,027$ & 0,028 \\
\cline { 2 - 5 } & $\mathrm{P}$ & 0,519 & 0,761 & 0,744 \\
\hline Spearman korelasyon testi, VAS: Vizüel analog skala, KMD: Kemik mineral dansitometri & & \\
\hline
\end{tabular}


koşulları nedeniyle bifosfonat kullanmayan veya bifosfonatlara intolere olmayan hastaların çalışmaya dahil edilememesi çalışmamızın temel kısıtıııklarındandır. Çalışmamızda; OP'deki tedavi başarısını, tedaviyi durdurma gerekliliğini ve tedaviye devamı değerlendirme açısından kolay elde edilebilir klinik bir değişken olan T-skorunu kullandık (23). Hasta sayımızın fazlalığı, hastalar ile yüz yüze görüşülmüş olması, hasta popülasyonumuzun homojen olarak 4 doz denosumab tedavisi almış postmenopozal hastalardan oluşması ve kliniği değiştirebilecek ek hastalıkların dışlanması çalışmamızın sonuçlarının güvenilirliğini artırmaktadır. Ülkemizde denosumab alan postmenopozal OP tanılı hastaların değerlendirildiği yeterli çalışma bulunmadığından çalışmamızın verilerinin literatüre katkı sağladığını düşünmekteyiz. Bu bakımdan denosumabın yaşam kalitesi, ağrı ve kemik mineral yoğunluğu üzerine etkinliğini araştırmak için randomize kontrollü ve uzun süreli takip edilen hasta grupları ile yapılan prospektif çalışmalara ihtiyaç vardır.

\section{Sonuç}

Denosumab tedavisi; Özellikle yaşlılarda, artmış kırık riski olanlarda, düzenli oral ilaç alımı uygun olmayanlarda, oral bisfosfonat tedavisi almakta güçlük çeken hastalarda veya bisfosfonat tedavisine cevapsız olan postmenopozal OP'li kadınlarda T-skorlarında belirgin iyileşme ve ağrı skalalarında anlamlı azalma sağlamaktadır. Etkinliği, olası yan etkilerin azlığı ve pratik kullanımı nedeniyle hastalarda sıklıkla memnuniyet sağlayarak güvenle kullanılabilecek bir tedavi seçeneğidir.

\section{Etik}

Etik Kurul Onayı: Bu çalışmanın yapılabilmesi için Sağlık Bilimleri Üniversitesi Erzurum Bölge Eğitim ve Araştırma Hastanesi Etik Kurul Komitesi'nden gereken etik kurul onayı alındı (karar no: 2020/14-59, tarih: 20.07.2020) ve çalışma Helsinki Bildirgesi'ne uygun olarak gerçekleştirildi.

Hasta Onayı: Hastaların yazılı onamı alınmıştır.

Hakem Değerlendirmesi: Editörler kurulu ve editörler kurulu dışında olan kişiler tarafından değerlendirilmiştir.

\section{Yazarlık Katkıları}

Cerrahi ve Medikal Uygulama: G.S., D.Ç.A., Konsept: G.S., Dizayn: G.S., D.Ç.A., Veri Toplama veya İşleme: G.S., D.Ç.A., Analiz veya Yorumlama: G.S., D.Ç.A., Literatür Arama: G.S., Yazan: G.S.

Çıkar Çatışması: Yazarlar tarafından çıkar çatışması bildirilmemiştir.

Finansal Destek: Yazarlar bu çalışma için herhangi bir finansal destek almadıklarını bildirmiştir.

\section{Kaynaklar}

1. Clynes MA, Harvey NC, Curtis EM, Fuggle NR, Dennison EM, Cooper C. The epidemiology of osteoporosis. Br Med Bull 2020;133:105-17.

2. Gennari L, Merlotti D, Falchetti A, Eller Vainicher C, Cosso R, Chiodini I. Emerging therapeutic targets for osteoporosis. Expert Opin Ther Targets 2020;24:115-30.
3. Warriner $\mathrm{AH}$, Saag KG. Osteoporosis diagnosis and medical treatment. Orthop Clin North Am 2013;44:125-35.

4. Compston J, Cooper A, Cooper C, Gittoes N, Gregson C, Harvey $\mathrm{N}$, et al. UK clinical guideline for the prevention and treatment of osteoporosis. Arch Osteoporos 2017;12:43.

5. Mcclung MR. Efficacy and Safety of Osteoporosis Treatment. In: Pocket Reference to Osteoporosis. Springer; Cham: 2019. p. 43-57.

6. Camacho PM, Petak SM, Binkley N, Clarke BL, Harris ST, Hurley $\mathrm{DL}$, et al. American Association Of Clinical Endocrinologists and American College of Endocrinology Clinical Practice Guidelines for the Diagnosis and Treatment of Postmenopausal Osteoporosis 2016. Endocr Pract 2016;22(Suppl 4):1-42.

7. Deeks ED. Denosumab: A Review in Postmenopausal Osteoporosis. Drugs Aging 2018;35:163-73.

8. Genant HK, Wu CY, van Kuijk C, Nevitt MC. Vertebral fracture assessment using a semiquantitative technique. J Bone Miner Res 1993;8:1137-48.

9. Kulaksızoğlu M. Denosumab in the Treatment of Osteoporosis. Turkiye Klinikleri J Endocrin-Special Topics 2017;10:95-100.

10. Wensel TM, Iranikhah MM, Wilborn TW. Effects of denosumab on bone mineral density and bone turnover in postmenopausal women. Pharmacotherapy 2011;31:510-23.

11. Cummings SR, San Martin J, McClung MR, Siris ES, Eastell R, Reid $I R$, et al (FREEDOM Trial). Denosumab for prevention of fractures in postmenopausal women with osteoporosis. N Engl J Med 2009;361:756-65

12. Lyu H, Jundi B, Xu C, Tedeschi SK, Yoshida K, Zhao S, et al. Comparison of Denosumab and Bisphosphonates in Patients With Osteoporosis: A Meta-Analysis of Randomized Controlled Trials. J Clin Endocrinol Metab 2019;104:1753-65.

13. Sheedy KC, Camara MI, Camacho PM. Comparison of the efficacy, adverse effects, and cost of zoledronic acid and denosumab in the treatment of osteoporosis. Endocr Pract 2015;21:275-9.

14. Freemantle N, Satram-Hoang S, Tang ET, Kaur P, Macarios D, Siddhanti S, et al. Final results of the DAPS (Denosumab Adherence Preference Satisfaction) study: a 24-month, randomized, crossover comparison with alendronate in postmenopausal women. Osteoporos Int 2012;23:317-26.

15. Kendler DL, McClung MR, Freemantle N, Lillestol M, Moffett $\mathrm{AH}$, Borenstein J, et al. Adherence, preference, and satisfaction of postmenopausal women taking denosumab or alendronate. Osteoporos Int 2011;22:1725-35.

16. Hiligsmann M, Dellaert BG, Dirksen CD, Watson V, Bours $S$, Goemaere $S$, et al. Patients' preferences for anti-osteoporosis drug treatment: a cross-European discrete choice experiment. Rheumatology (Oxford) 2017;56:1167-76.

17. Özsoy-Ünübol T, Akyüz G, Mirzayeva S, Güler T. Evaluation of pain, quality of life, and patient satisfaction in parenterally treated patients with postmenopausal osteoporosis. Turk J Phys Med Rehabil 2020;66:262-70.

18. Dempster DW. Osteoporosis and the burden of osteoporosisrelated fractures. Am J Manag Care 2011;17 Suppl 6:S164-9.

19. Makras P, Vaiopoulos G, Lyritis GP; Greek National Medicine Agency. 2011 guidelines for the diagnosis and treatment of osteoporosis in Greece. J Musculoskelet Neuronal Interact 2012;12:38-42.

20. Hiligsmann M, Reginster JY. Potential cost-effectiveness of denosumab for the treatment of postmenopausal osteoporotic women. Bone 2010;47:34-40.

21. Albert SG, Reddy S. Clinical Evaluation of Cost Efficacy of Drugs for Treatment of Osteoporosis: A Meta-analysis. Endocr Pract 2017;23:841-56.

22. Adami S, Isaia G, Luisetto G, Minisola S, Sinigaglia L, Gentilella $R$, et al. Fracture incidence and characterization in patients on osteoporosis treatment: the ICARO study. J Bone Miner Res 2006;21:1565-70.

23. Ferrari S, Libanati C, Lin CJF, Brown JP, Cosman F, Czerwiński E, et al. Relationship Between Bone Mineral Density T-Score and Nonvertebral Fracture Risk Over 10 Years of Denosumab Treatment. J Bone Miner Res 2019;34:1033-40. 